\title{
Population status and conservation of bats (Chiroptera) in Kenting National Park, Taiwan
}

\author{
Minna J. Hsu
}

This paper presents the results of field work conducted between 1994 and 1996 to establish the occurrence, and population, breeding and conservation status of bats in and around Kenting National Park, southern Taiwan. Of the 20 bat species that occur in Taiwan, Kenting National Park and its vicinity harbour eight species; three are endemic to Taiwan and two are endemic subspecies. Six of the eight species roost in natural caves and man-made tunnels. Two species of forest bats were captured during mist-netting. The most predominant species were the horseshoe bat Rhinolophus monoceros and the common bent-winged bat Miniopterus schreibersii. The major threat for the cave-dwelling bats around Kenting is the closure of cave entrances by farmers. Recommendations are given for conserving the bats and their habitats in Taiwan.

\section{Introduction}

Over 950 species of bats (Order: Chiroptera) are known world-wide, comprising about one-quarter of the living mammalian fauna (Kunz, 1982). Bats play a major role in forest ecosystems by pollinating plants, dispersing seeds and controlling insect populations (Kunz, 1988; Thomas, 1988; Whitaker, 1988). With 59 genera in eight families, Asia ranks second to the neotropical region in the diversity of bats (Wilson, 1989). The continuing deforestation, habitat alteration, industrialization and expansion of agricultural activities threaten the survival of bats in many parts of Asia. Unless steps are taken to decelerate or reverse the current rate of loss of forest habitats to alternative land uses, the ecological diversity of bat fauna may never be fully understood (Kunz, 1982).

Taiwan covers an area of $36,000 \mathrm{sq} \mathrm{km}$ and is located at the fringe of the Asian continental shelf on the western rim of the Pacific basin. It is separated from mainland China by a strait that is just $130 \mathrm{~km}$ wide at its narrowest point. Taiwan is dominated by a range of high mountains and has a diverse flora of over 4000 vascular plants and six forest types (Boufford et al., 1996). Its rapid economic development and industrial growth have put heavy pressure on the forest ecosystems. Over the last decade, the government of Taiwan has been keenly concerned about the industrial revolution and its impact on Taiwan's natural resources (Chang et al., 1989). To date, six national parks, 18 nature reserves and 24 nature protected areas have been designated to ensure protection for wildlife and natural habitats (Yang, 1993). The protected area covers 440,290 ha, which is 12.2 per cent of the total land area of Taiwan.

Very little is known about the occurrence, distribution, population status and ecology of bats in Taiwan. Chen (1956) reported the occurrence of 22 species of bats but recent surveys recorded the presence of 20 species in Taiwan (Cheng, 1995; Table 1). One of the taxa recorded by Chen (1956), the Formosan flying fox Pteropus dasymallus formosus, which was endemic to Taiwan, has since become extinct in the wild as a result of deforestation and hunting (Hsu, 1996). This subspecies, the only member of the Megachiroptera recorded from Taiwan, was known only from $15-\mathrm{sq}-\mathrm{km}$ Green 
Island in Taitung County in recent years. Two of the taxa recorded by Cheng (1995), Myotis sp. and Barbastella sp., have yet to have their identities confirmed and the list includes a new species of long-eared bat, Plecotus taivanus, which was recorded in the central mountains of Taiwan (Yoshiyuki, 1991). Two of the species reported by Chen (1956), the bicoloured leaf-nosed bat Hippisideros bicolor and Scotozous dormeri, have yet to be reconfirmed in Taiwan. Preliminary information on the reproduction of the Japanese pipistrelle Pipistrellus abramus from northern Taiwan has been reported (Lee, 1995).

This paper presents data for the first time on the population, distribution, breeding and conservation status of bats around Kenting National Park, southern Taiwan.

\section{Study site and bat survey}

The present study of bat populations was carried out in Kenting National Park $\left(21^{\circ} 90^{\prime} \mathrm{N}\right.$, $120^{\circ} 80^{\prime} \mathrm{E}$ ), located at the southernmost tip of Taiwan (Figure 1). Kenting National Park was established in January 1984 and was the first national park of Taiwan. The park is bordered on three sides by water, the Pacific Ocean to the east, the Bashi Channel to the south, and the Taiwan Strait to the west. It covers 17,731 ha of land and 14,900 ha of adjacent ocean (Yang, 1993). The ecosystems of the Kenting National Park range from grassland to tropical rain forest and contain an estimated 2200 plant species. Kenting National Park has several uplifted coral reefs and limestone caves, which provide ideal roosting sites for bats.

Table 1. Bat species recorded in Taiwan and their roosting habits (taxonomy after Corbet and Hill, 1992)

\begin{tabular}{|c|c|c|}
\hline \multicolumn{2}{|c|}{ Family, English and scientific name of species } & \multirow[t]{2}{*}{ Main roost sites } \\
\hline Family: Pteropodidae & & \\
\hline Formosan flying-fox & Pteropus dasymallus formosus Ext & Trees \\
\hline \multicolumn{3}{|l|}{ Family: Rhinolophidae } \\
\hline Woolly horseshoe bat & Rhinolophus luctus formosaet & Caves, buildings \\
\hline Horseshoe bat & R. monoceros* & Caves, tunnels \\
\hline \multicolumn{3}{|l|}{ Family: Hipposideridae } \\
\hline Himalayan leaf-nosed bat & Hipposideros armiger terasensist & Caves, tunnels, buildings \\
\hline Tail-less leaf-nosed bat & Coelops frithii formosanust & Tunnels \\
\hline \multicolumn{3}{|l|}{ Family: Vespertilionidae } \\
\hline Common bent-winged bat & Miniopterus schreibersii & Caves, tunnels \\
\hline Taiwanese long-eared bat & Plecotus taivanus* & Tree \\
\hline Lesser yellow house bat & Scotophilus kuhlii & Buildings, trees, bird nests \\
\hline Mouse-eared bat & Myotis muricola orii & Unknown \\
\hline Hodgson's bat & Myotis formosus wataseit & Attics, buildings \\
\hline Large-footed myotis & Myotis taiwanensis* & Caves, tunnels, buildings \\
\hline- & Myotis sp. $\ddagger$ & Unknown \\
\hline Noctule & Nyctalus noctula & Unknown \\
\hline Japanese pipistrelle & Pipistrellus abramus & Attics, buildings \\
\hline Eastern parti-coloured bat & Vespertilio orientalis & Buildings, tunnels, bridges \\
\hline Taiwanese tube-nosed bat & Murina puta* & Trees \\
\hline Serotine & Eptesicus serotinus horikawai & Trees \\
\hline Hairy-winged bat & Harpiocephalus harpia & Trees \\
\hline- & Barbastella sp. $\ddagger$ & Unknown \\
\hline \multicolumn{3}{|l|}{ Family: Molossidae } \\
\hline European free-tailed bat & Tadarida teniotis insignis & Unknown \\
\hline
\end{tabular}

Ex extinct in wild; *endemic species; tendemic subspecies; $\neq$ species name not confirmed 
Figure 1. Map of Kenting National Park and the location of bat caves $(\mathrm{C} 1$ to $\mathrm{C} 8)$ and tunnels (T1 to T3). Open circles represent towns, broken lines represent roads, the thick solid line shows the land boundary and the thin solid line represents the boundary of the park including the marine area.

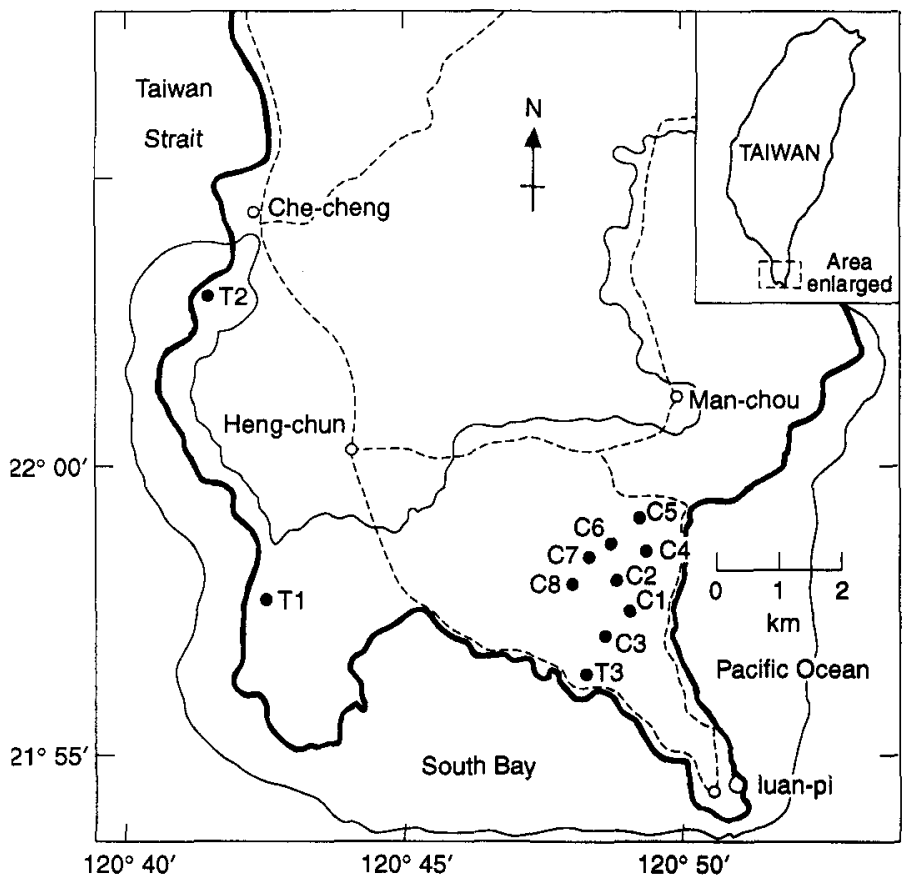

Table 2. Species composition and maximum population size of bats inhabiting caves and tunnels around Kenting National Park, Taiwan

\begin{tabular}{|c|c|c|}
\hline $\begin{array}{l}\text { Tunnel } \\
\text { (T) or } \\
\text { cave (C) }\end{array}$ & Species name & $\begin{array}{l}\text { Maximum } \\
\text { population } \\
\text { size }\end{array}$ \\
\hline \multirow[t]{3}{*}{$\mathrm{T} 1$} & Rhinolophus monoceros* & 4000 \\
\hline & Miniopterus schreibersii ${ }^{*}$ & 150 \\
\hline & Hipposideros armiger terasensis & 4 \\
\hline $\mathrm{T} 2$ & Rhinolophus monoceros* & 500 \\
\hline \multirow[t]{4}{*}{ T3 } & Rhinolophus monoceros & 200 \\
\hline & Coelops frithii formosanus* & 40 \\
\hline & Hipposideros armiger terasensis & 50 \\
\hline & Miniopterus schreibersii & 2 \\
\hline \multirow[t]{3}{*}{$\mathrm{C} 1$} & Rhinolophus monoceros & 5000 \\
\hline & Miniopterus schreibersii & 3000 \\
\hline & Myotis taiwanensis & 100 \\
\hline \multirow[t]{2}{*}{$\mathrm{C} 2$} & Miniopterus schreibersii* & 6000 \\
\hline & Myotis taiwanensis* & 400 \\
\hline $\mathrm{C} 3$ & Hipposideros armiger terasensis* & 200 \\
\hline C4 & Hipposideros armiger terasensis* & 1000 \\
\hline \multirow[t]{3}{*}{ C5 } & Rhinolophus monoceros & 30 \\
\hline & Miniopterus schreibersii & 5 \\
\hline & Rhinolophus luctus formosae & 2 \\
\hline C6 & Hipposideros armiger terasensis* & 35 \\
\hline $\mathrm{C} 7$ & Hipposideros armiger terasensis* & 50 \\
\hline $\mathrm{C} 8$ & Hipposideros armiger terasensis* & 120 \\
\hline
\end{tabular}

*Presence of pregnant or lactating females 
bats were estimated by using roost counts (Kunz et al., 1996). In addition, visual counts were carried out while the bats emerged by positioning two to three observers near the entrances of caves and tunnels. Mist-netting was used in the forest area. For each capture, I recorded the location, capture time, band number, sex, age, forearm length, length of head, body and tail, weight, lactational status, and presence or absence of embryos (detectable by palpation only during late gestation).

\section{Results}

\section{Population status}

Eight species of bats belonging to three families were recorded during this study. Six of them were recorded in caves and tunnels: the horseshoe bat Rhinolophus monoceros, woolly horseshoe bat R. luctus formosae, Himalayan leaf-nosed bat Hipposideros armiger terasensis, tail-less leaf-nosed bat Coelops frithi formosanus, common bent-winged bat Miniopterus schreibersii and large-footed myotis Myotis taiwanensis (Table 2). Two species - mouse-eared bat Myotis muricola and Taiwanese tube-nosed bat Murina puta - were recorded only during mist-netting in the forest area. These species were not observed roosting in caves and tunnels. It appears that these two species are forest bats and more surveys are needed to establish their population status. Three of the above species are endemic to Taiwan and two are endemic subspecies (Table 1). The predominant species were R. monoceros and $M$. schreibersii. Their maximum population sizes at a given roosting site were estimated to be 5000 and 6000 , respectively. Large congregations of $H$. a. terasensis numbering a maximum of $\mathbf{1 0 0 0}$ individuals were also recorded. The populations of $R$. monoceros, $M$. schreibersii and H.a.terasensis in Kenting appear to be healthy because all three species were seen in large colonies of over 1000 individuals. However, the population sizes of three other cave-dwelling bats were low. Maximums of 100 and 400 individuals of $M$. taiwanensis were estimated in caves $\mathrm{C} 1$ and $\mathrm{C} 2$, respectively
(Table 2). A total of 40 C.f. formosanus were seen in tunnel T3. Only two R. l. formosae were recorded on only one occasion in cave C5 (Table 2).

\section{Breeding status}

During this study, either pregnant or lactating females were recorded for all species with the exception of the $R$. l. formosae.

Both sexes of $R$. monoceros congregated in cave $C 1$ outside the breeding season but during the breeding season (April-August), only the males stayed there, the females dispersing elsewhere. In the breeding season M. schreibersii shared cave $\mathrm{C} 1$ with male $R$. monoceros and the $M$. schreibersii females nursed their young there.

In cave $C 2, M$. schreibersii females nursed their young with $M$. taiwanensis females and thus formed a single large colony of sympatric bats. A few $M$. taiwanensis males were also found in cave $\mathrm{C} 2$.

No lactating $M$. schreibersii were found in the tunnels. Maternity colonies of $R$. monoceros were found in only two of the three tunnels (T1 and T2). The third tunnel T3 was only used by C.f. formosanus as a nursing site, but was shared with both male and female $R$. monoceros and male H.a.terasensis. Similar cases of sympatric bats sharing roosts and partitioning resources have been reported among insectivorous bats (Kunz, 1982; RodriguezDuran, 1987).

In cave $C 4, H$. a. terasensis assembled largely during winter but both sexes dispersed during the breeding season. Three other caves $(C 6, C 7$ and C8) were also found to be used by H.a. terasensis as maternity sites with nursing colonies of 35, 50 and 120 individuals, respectively (Table 2). No other species of bats shared the maternity sites with $H$.a.terasensis. One partial albino H.a.terasensis was recorded during this study. The occurrence of true albinism or partial albinism has been rarely reported among insectivorous bats (Hill and Smith, 1984).

Single individuals of $M$. puta and M. m. orii were captured during mist netting in the forest. In addition one dead specimen of 


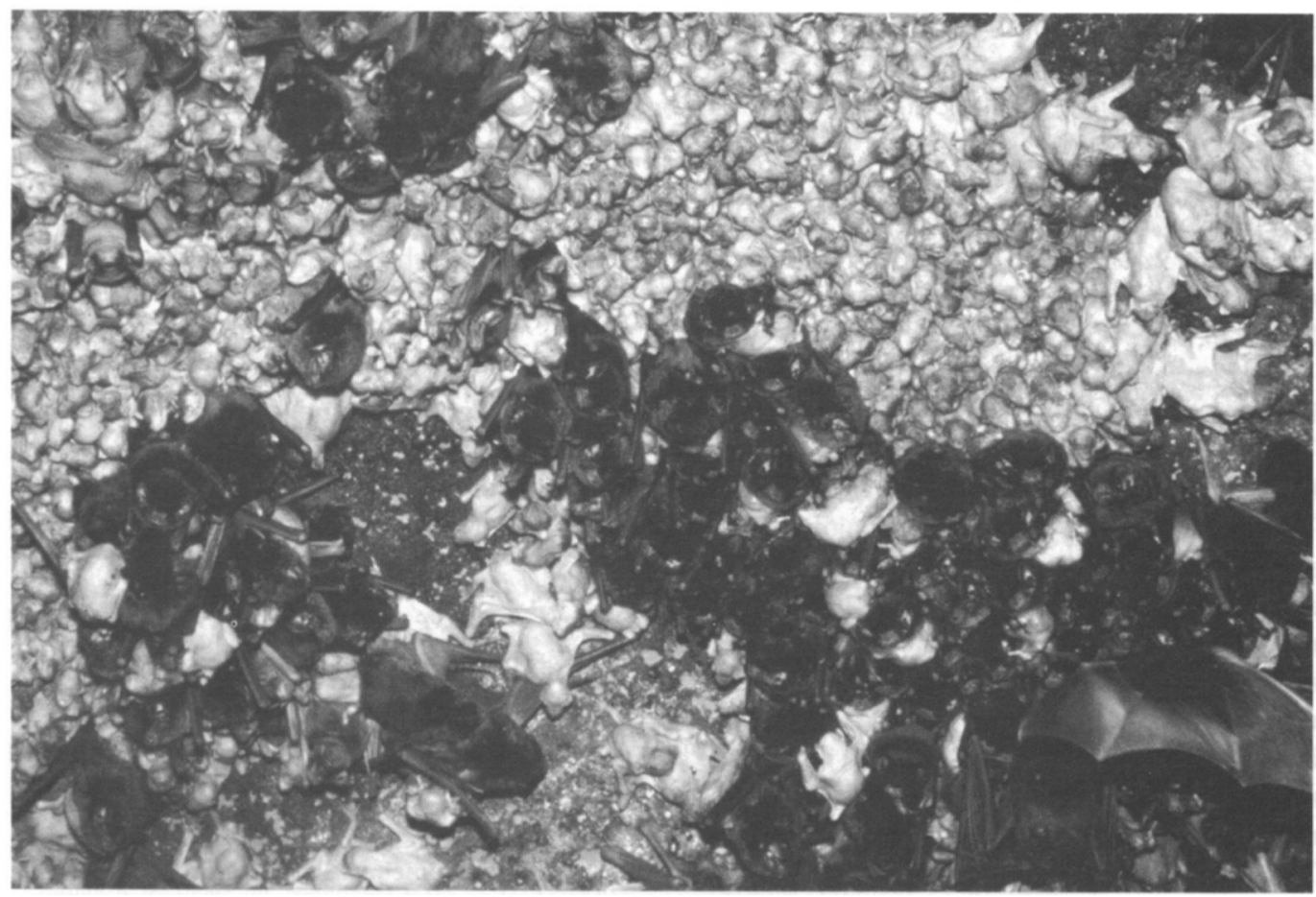

Maternity colony of common bent-winged bats Miniopterus schreibersii (Minna J. Hsu).

Taiwanese tube-nosed bat collected in Kenting had twin foetuses of different sexes. The specimen has been deposited at the National Museum of Natural History, Smithsonian Institution.

\section{Discussion}

Threats to bats

Caves are essential roosting sites for many species of bats throughout the world (Kunz and Pierson, 1994). Of the 39 bat species that occur in the USA, at least 18 depend heavily on caves for roosting (McCracken, 1989). Similarly, 60 of the 134 bat species found in Mexico regularly roost in caves (Arita, 1993).

Six of the eight species observed in this study and seven of the 19 species that now occur in Taiwan are known to depend on caves or tunnels for roosting (Tables 1 and 2). Several of these caves in Kenting are close to farms. The main threats to bats in Kenting are the closure of roosting caves as a result of habitat alteration. Seven caves in Kenting National Park have been completely buried by farmers to expand their agricultural fields over the last few years. Steps must be taken to restore the caves buried by soil, to decelerate the expansion of encroachment by local villagers and increase public education to save bat habitats. Bats have also been used in Chinese medicine. It is believed that medicine made from bats can cure respiratory diseases. However, the extent of bat harvest for medicinal use in Taiwan is not known and needs further investigation. Furthermore, future studies should also focus on the impact of tourists in bat roost sites so that better management plans can be prepared.

\section{Conservation of bats}

The only bat protected by the Wildlife Conservation Law of the Republic of China on Taiwan (1989) is Pteropus dasymallus formosus, which is extinct in the wild. Despite the lack of quantitative data on the population status of 
bats in Taiwan, it is important to consider endemic species, such as Rhinolophus monocerus, Plecotus taivanus, Myotis taiwanensis and Murina puta for inclusion in the list of protected wildlife. In addition, priority should be given to protect the small numbers of Coelops frithii formosanus and Rhinolophus luctus formosae and their roosting sites in Kenting National Park.

Four species of bats use the tunnels in Kenting National Park for roosting (Table 2). Tunnel T3 houses the only maternity colony known for Coelops frithii formosanus in Taiwan. Tunnels $\mathrm{T} 1$ and $\mathrm{T} 2$ are also the major nursing sites for $R$. monoceros. These tunnels are easily accessible to people, who may disturb the roosting colonies of bats. The national park should build gates to restrict the entry of unauthorized people and erect signs explaining why the tunnels are closed. The same methods should be used to safeguard bat roosts in abandoned tunnels throughout Taiwan

Kenting National Park attracts about 3 million tourists every year from throughout Taiwan. The park is promoting wildlife conservation among visitors through education and interpretation by using pictures, postcards, slides and videos of the landscapes as well as glamorous species such as; sika deer, migratory ducks and raptors. The national park's education department should also consider educating the public about nocturnal bat species. Furthermore, the park should develop community-based bat conservation educational programmes. Such programmes are vital to raise conservation awareness among the local people who live in the national park.

Infra-red video cameras could be established in caves and tunnels around Kenting for public viewing of colonial roosting and maternity colonies of bats. The visitors would be able to learn more about the ecology, population and behaviour of insectivorous bat communities. An infra-red camera system has been used successfully to allow the public to view a bat maternity cave in south-eastern Australia, which houses about 200,000 common bent-winged bats Miniopterus schreibersii (L. Conolie, pers. comm.).
Bats have long been symbolized to bring good fortune and happiness in Chinese culture. The pronunciation of ' $F u^{\prime}$ means bat as well as good luck or good fortune. This has resulted in bats having a favourable image amongst Chinese people. A common Chinese symbol is a peach tree surrounded by five flying bats. The bats represent five concepts: health, wealth, happiness, longevity and a peaceful death (Ades, 1995). Although bats are a symbol of good fortune for the Chinese community in Taiwan, their very survival lies in the hands of the people.

\section{Acknowledgements}

I am grateful to Professor Y. S. Hsu for donating a field vehicle to carry out the bat survey. The staff of Kenting National Park and the Forestry Research Institute's field station gave permission to work in the Kenting area. I am grateful to Mr. M. S. Pan, who taught me to handle vipers in bat caves and am thankful to the students, T. Y. Huang, N. Wu and P. C. Loung who joined me in the search for bats. G. Agoramoorthy and two anonymous reviewers provided critical comments on the manuscript of an earlier version.

\section{References}

Ades, G. 1995. Bats of Hong Kong. Island House Conservation Studies Center, Hong Kong.

Arita, H.T. 1993. Conservation biology of the cave bats of Mexico. Journal of Mammalogy, 74 (3), 693-702.

Boufford, D.E., Hsieh, C.F., Huang, T.C., Ohasi, H., Yang, Y.P. and Lu, S.Y. 1996. Flora of Taiwan. 2nd Edn. Editorial Committee of the Flora of Taiwan, Taipei, Taiwan, ROC.

Chang, Y.C., Chiang, P.C., Chu, Y.P., Hsiao, H. and Severinghaus, L.L. 1989. Taiwan 2000. Balancing Economic Growth and Environmental Protection. Steering Committee of the Taiwan 2000 Study, Academia Sinica, Taipei, Taiwan, ROC.

Chen, J.T.F. 1956. A Synopsis of the Vertebrates of Taiwan. Taiwan Commercial Press, Taipei, Taiwan. (In Chinese).

Cheng, H.C. 1995. Bats in Taiwan. Taipei Zoo Quarterly, 15 (4), 4-12. (In Chinese).

Corbet, G.B. and Hill, J.E. 1992. The Mammals of the Indomalayan Region: A Systematic Review. Oxford University Press, Oxford.

Hill, J.E. and Smith, J.D. 1984. Bats: A Natural History. University of Texas Press, Austin. 
Hsu, M.J. 1996. On the occurrence of microbats in Taiwan. Bat Research News, 37 (4), 108-110.

Hsu, J.M. and Lin, Y.S. 1993. Morphology, sexual dimorphism and hybridization in Styan's bulbul Pycnonotus taivanus and Chinese bulbul Pycnonotus sinensis formosae in Taiwan. Acta Zoologica Taiwanica, 4, 103-111.

Hsu, J.M. and Lin, Y.S. 1994. The annual cycle of the Chinese bulbul Pycnonotus sinensis formosae in Taiwan. Acta Zoologica Taiwanica, 5, 33-39.

Hsu, J.M. and Lin, Y.S. 1997. Breeding ecology of Styan's bulbul Pycnonotus taivanus in Taiwan. Ibis (in press).

Kunz, T.H. 1982. Ecology of Bats. Plenum Press, New York.

Kunz, T.H. 1988. Ecological and Behavioural Methods for the Study of Bats. Smithsonian Institution Press, Washington, DC.

Kunz, T.H. and Pierson, E.D. 1994. Bats of the world: an introduction. In Walker's Bats of the World (ed. R. M. Nowak), pp. 1-46. The John Hopkins University Press, Baltimore.

Kunz, T.H., Thomas, D.W., Richards, G.C., Tidemann, C.R., Pierson, E.D. and Racey, P.A. 1996. Observational techniques for bats. In Measuring and Monitoring Biological Diversity: Standard Methods for Mammals (eds D. E. Wilson, F. R. Cole, J. D. Nichols, R. Rudran and M.S. Foster), pp. 105-114. Smithsonian Institution Press, Washington, DC.

Lee, L.L. 1995. A preliminary study on the reproductive patterns of Pipistrellus abramus in northern Taiwan. Acta Zoologica Taiwanica, 6 (1), 61-66.
McCracken, G.F. 1989. Cave conservation: special problems of bats. Bulletin of the National Speleological Society, 51, 47-51.

Rodriguez-Duran, A. 1987. Patterns of population size, diet, and activity time for a multispecies assemblage of bats at a cave in Puerto Rico. Caribbean Journal of Science, 23 (3-4), 352-360.

Thomas, D.W. 1988. Analysis of diets of plant-visiting bats. In Ecological and Behavioural Methods for the Study of Bats (ed. T. H. Kunz), pp. 211-220. Smithsonian Institution Press, Washington, DC.

Whitaker, Jr. J.O. 1988. Food habits analysis of insectivorous bats. In Ecological and Behavioural Methods for the Study of Bats (ed. T. H. Kunz), pp. 171-189. Smithsonian Institution Press, Washington, DC.

Wildlife Conservation Law. 1989. Republic of China's Wildlife Conservation Law 1-3266. Government of the Republic of China on Taiwan.

Wilson, D.E. 1989. Bats. In Tropical Rain Forest Ecosystems (eds H. Lieth and M. J. A. Werger), pp. 365-382. Elsevier Science Publishers, Amsterdam.

Yang, H.L. 1993. Nature Conservation in Taiwan ROC. Council of Agriculture, Taipei.

Yoshiuki, M. 1991. A new species of Plecotus (Chiroptera, Vespertilionidae) from Taiwan. Bulletin of the National Science Museum, Tokyo. Series A (Zoology), 17 (4), 189-195.

Minna J. Hsu, Department of Biology, Graduate Institute of Life Sciences, National Sun Yat-sen University, Kaohsiung 80424, Taiwan, Republic of China. 